\title{
DEL SOPORTE PAPEL AL DIGITAL: UN ANTES Y UN DESPUÉS PARA LOS DERECHOS FUNDAMENTALES
}

\author{
Rosa María García SANZ \\ Sección Departamental de Derecho Constitucional \\ Facultad de Ciencias de la Información \\ Universidad Complutense de Madrid \\ rosamaga@ucm.es
}

\section{RESUMEN}

La digitalización de la información en Internet no ba sido un mero cambio de soporte. El paso del analógico al digital ba supuesto un gran impacto sobre factores como el tiempo y el espacio, con consecuencias jurídicas de gran magnitud. Los derechos fundamentales se ban visto afectados en su contenido y en su ejercicio, y se han vuelto conflictivos en algunos contextos. La evolución jurisprudencial permite identificar algunos cambios de gran trascendencia y entender algunos fenómenos que se producen en la red.

Palabras clave: derechos fundamentales en Internet, derecho a la información, derechos digitales, Constitución, jurisprudencia.

\section{ABSTRACT}

Digitalisation of information on Internet bas merely been a change of support. Change from analog to digital systems has brought a great impact on factors such as time and space, with legal consequences of great scope. Basic rights have been affected in content or put into practice and have become troublesome in certain contexts. The evolution of case law has allowed us to spot certain big changes and to understand certain facts which take place on the web.

Keywords: Basic rights on the Internet, the right to information, digital rights, Constitution, Case Law

\section{ZUSSAMENFASSUNG}

Die Digitalisierung der Information im Internet war kein bloßer Datenträgerwechsel. Der Schritt von analog zu digital hatte große Auswirkungen auf Faktoren wie Zeit und Raum, mit juristischen Folgen von großer Tragweite. Die Grundrechte wurden sowobl in Bezug auf ibre Inbalte als auch in ibrer Ausübung berübrt, und es entstehen stellenweise Konflikte. Die Entwicklung der Rechtsprechung ermöglicht es, einige Veränderungen von großer Transzendenz aufzuzeigen und bilft, einige der Pbänomene, die im Internet auftreten, zu verstehen.

Schlüsselwörter: Grundrechte im Internet, Recht auf Information, digitale Rechte, Verfassung, Rechtsprechung. 
SUMARIO: I. INTRODUCCIÓN.-II. IMPACTO EN LOS FACTORES TIEMPO-ESPACIO.-III. LA DIFÍCIL RELACIÓN ENTRE TÉCNICA Y DERECHO.-IV. TODA LA INFORMACIÓN SON DATOS: LA CRISIS DE LA PRIVACIDAD.-V. CONCLUSIONES.

\section{INTRODUCCIÓN}

La relación intrínseca entre los derechos fundamentales de libertad de información y expresión y el principio de legitimidad democrática (soberanía popular) es ya lugar común en el Derecho constitucional del mundo occidental. Los profundos cambios que experimenta el ejercicio del derecho a la información en el contexto digital de Internet afectan también a otros derechos fundamentales, sin duda alguna en el derecho a la privacidad o en el derecho de participación. Esta afectación de derechos fundamentales, tan esenciales para el funcionamiento de la democracia, está provocando una importante crisis en sus instituciones. Señala Yochai Benkler ${ }^{1}$ que «for more than 150 years, modern complex democracies have depended in large measure on an industrial information economy for these basic functions, and the change brought about by the networked information environment is deep». En la topografía que Internet muestra, las posibilidades de creación y formas de producción y difusión de información superan los modelos tradicionales (con los que convive) y provocan importantes cambios estructurales: «It goes to the very foundations of how liberal markets and liberal democracies have coevolved for almost two centuries» ${ }^{2}$. En el ecosistema global de Internet (redes sociales, webs, plataformas digitales, blogs, IP TV, etc.) se ha producido una sucesión de hechos en relación con las noticias o información en general, que va desde el debilitamiento de las «hard news» (noticias de interés general) al auge de las «soft news» (noticias de interés humano y entretenimiento), para finalmente asistir a la expansiva erupción de «fake news» (noticias falsas) ${ }^{3}$.

La crisis que sufre «la producción de noticias» refleja la crisis de los modelos empresariales de prensa en Internet, y refleja también la crisis misma de la función de los medios de comunicación en el sistema democrá-

${ }^{1}$ Y. Benkler, The Wealth of Networks. How Social Production Transforms Markets and Freedom, New Haven-London, Yale University Press, 2006, p. 1.

${ }^{2}$ Ibid., pp. 1 y 388.

3 C. PAuner Chulvi, «Noticias falsas y libertad de expresión e información. El control de los contenidos informativos en la red», Teoría y Realidad Constitucional, núm. 41 (2018), p. 299. 
tico y la crisis de la democracia misma en un mundo digital. El cambio del elemento técnico - del soporte- no es ajeno a todas estas transformaciones. Siendo cierto que la producción de «información» en Internet se caracteriza por una abundancia sin precedentes, también lo es su «escasez» de noticias con características de calidad. Calidad que se describe no solo por la actualidad y/o inmediatez, sino también por la autenticidad, credibilidad y responsabilidad. Esto podría socavar el modelo democrático de convivencia. Si la tendencia a producir «soft news» (noticias de interés humano y entretenimiento) era predominante en los medios de comunicación convencionales, esta continúa intensificándose en Internet, donde la producción de «hard news» (noticias de interés general) es incluso menos atractiva y rentable: «Laments that the rise of soft news reflect a general decline in tastes also miss the economic factors driving news content (hard news/soft news). Consumers today can choose from a wide spectrum of news products that vary in their emphasis of news about government and politics (hard news) or human interest and entertainment figures (soft news)» ${ }^{4}$. Tendencia que finalmente ha desembocado en las «fake news» (información falsa) en las redes sociales, principalmente, causando gran confusión en la opinión pública.

En esta evolución no se puede ignorar la variable económica: el análisis económico no pierde de vista el comportamiento de la publicidad en formato digital que, aunque representa un mercado de gigantescas dimensiones, resulta desconsolador en cuanto a su composición para los productores de noticias. Y es que las grandes tecnológicas con Google a la cabeza, Apple, Facebook o Amazon (citando algunas muy importantes) son los destinos preferidos de los anunciantes y de la publicidad ${ }^{5}$. Las posibilidades de ofrecer y difundir información en la web se incrementan con éxito mediante todo tipo de dispositivos (sea por teléfono móvil, tabletas, desktop o laptop) y mediante las sinergias de redes sociales, motores de búsqueda, emails, blogs, agregadores y todas las demás posibles. Podría pensarse, en consecuencia, en grandes ingresos por publicidad, pero la publicidad en Internet prefiere otros espacios y contenidos, y resulta para la prensa digital de «escaso valor económico» hasta el momento. Es por

${ }^{4}$ J. T. Hamilton, All the News that's Fit to Sell. How the Market Transforms Information into News, New Jersey, Princeton University Press, 2004, p. 113

5 Resulta, cuando menos, curioso observar cómo en Europa se ven las grandes tecnológicas como la gran amenaza para la viabilidad de la «prensa», y en Estados Unidos se pone en el ojo del huracán a las agregadoras de todo tipo y tamaño que nada tienen que ver con la fortaleza de Google o Facebook, por ejemplo. Intuitivamente, parece que la llamada «economía de la atención» centra más el debate en Estados Unidos que en Europa. 
ello que muchos «periódicos» digitales avanzan por el camino que conduce al pago por sus contenidos usando fórmulas posibles (suscripción en diferentes formatos, pay wall, micropago por noticias, archivos disponibles bajo pago para los recientes meses, etc.). Camino que sí lleva a alguna parte, siempre que se ofrezca contenido «diferenciado», exclusivo, lo que requiere recursos para un periodismo de calidad. Y es que parece que nadie renunciará al «gratis» por contenidos que están en todas partes, salvo que el fin de la llamada «net neutrality» fuerce a su extinción ${ }^{6}$, si es que se desea un servicio de transmisión de calidad ${ }^{7}$.

Los informes tanto de la Comisión Europea ( $\ll$ A multi-dimensional approach to disinformation. Report of the independent High level Group on fake news and online disinformation», publicado en marzo 2018) como del Pew Research Center's Project for Excellence in Journalism («The Future of Truth and Misinformation Online») ${ }^{8}$ pueden ayudar a entender la situación actual.

El cambio de soporte del analógico (papel) al digital, que domina en Internet global, ha tenido un enorme impacto en los derechos fundamentales, a cuyas consecuencias todavía asistimos e intentamos entender. Los derechos de propiedad intelectual, los de protección de datos personales, los de privacidad e intimidad o el derecho a la libre información y expresión, entre otros, parecen estar en plena transformación a consecuencia de este extraordinario impacto. En un esfuerzo por comprender estos profundos cambios que se han producido, se utilizarán algunos argumentos de notables casos jurisprudenciales ${ }^{9}$ con el fin de identificar los factores clave

${ }^{6}$ Vid., por todos, T. Wu, The Master Switch. The Rise and Fall of Information Empires, New York, Alfred A. Knopf, 2010. Vid. también mi trabajo en relación con la Unión Europea, R. M. GARCía SANZ, «Internet neutral como principio jurídico de igualdad en las Directivas de Telecomunicaciones de la Unión Europea (2009)», en Constitución y desarrollo político. Estudios en homenaje al profesor Jorge de Esteban, Valencia, Tirant lo Blanch, 2013, p. 1587.

7 R. S. LeE y T. Wu, «Subsidizing Creativity Through Network Design: Zero Pricing and Net Neutrality», Journal of Economic Perspectives, vol. 23, núm. 3 (2009), pp. 61-76.

${ }^{8}$ Pew Research Center's Project for Excellence in Journalism, «The Future of Truth and Misinformation Online», octubre de 2017, disponible en www.pewresearch. org. Vid. también Comisión Europea, «Report of the Independent High Level Group on Fake News and Online Disinformation», Directorate-General 2018, disponible en bttp:// ec.europa.eu/newsroom/dae/document.cfm?doc_id=50271. A multi-dimensional approach to disinformation - Report of the independent High level Group on fake news and online disinformation.

${ }_{9}$ Para un estudio en profundidad de estos casos vid. R. M. GARCía SAnZ, Digital Journalism. Rethinking Communication Law to Support Democracy and Viable Business Models, Palo Alto, Academica Press, 2017. 
de estos cambios. Pronunciamientos judiciales antes y después de Internet. Se trata de jurisprudencia tanto del Tribunal Supremo americano como del Tribunal de Justicia de la Unión Europea en general, aunque se hace referencia a algún caso de algún tribunal menor. Casos tomados de los últimos diez años, lo que permite describir una evolución histórica que confiere perspectiva para entender los problemas que actualmente estamos viviendo. En este proceso se ha detectado una transformación de los parámetros tiempo-espacio. Igualmente, al cambiar el soporte técnico se observa que algunos derechos cambian su comportamiento: a veces decaen o no se activan, y, en otras ocasiones, surgen nuevos aspectos o nuevos derechos (un ejemplo es el derecho al olvido).

\section{IMPACTO EN LOS FACTORES TIEMPO-ESPACIO}

Tanto al otro lado del Atlántico como en Europa (Estados Unidos/ Unión Europea), el problema es el mismo allí como aquí: una crisis sin precedentes de los «periódicos de papel», primero, y de los «periódicos digitales» en Internet, después, para, finalmente, asistir a un fenómeno de «desinformación» desconocido. Las «fake news» han encontrado, en el contexto técnico y sociojurídico de las redes sociales, su principal medio ambiente, aunque no el único. Tal crisis de la información amenaza el modelo de convivencia democrática, al quedar derechos fundamentales, dependientes del derecho a la información y expresión, «desabastecidos».

El viejo problema de cómo proteger las noticias publicadas por los medios de comunicación (analógico) resurge de nuevo en Internet (digital). Las dos tradiciones jurídicas (europea y anglosajona) replantean el «viejo problema», que resurge «nuevo» en Internet. La cuestión no es baladí, pues de ello depende que la producción de información sea rentable y se pueda mantener un nivel de calidad. Si en los medios tradicionales ni los derechos de autor ni la llamada «hot news doctrine» (periodo de duración del valor de la noticia), unida a la «misappropriation» (apropiación indebida), terminaron de dar una respuesta del todo satisfactoria, ahora se vuelve más insatisfactoria que nunca. Sin embargo, entonces los factores tiempo y espacio eran firmes: el espacio hacía posible la delimitación de los mercados y el tiempo el rendimiento para recuperar la inversión propia. Esto en Internet se ha desvanecido. La llamada «ventaja del primer movimiento» tampoco reporta beneficios a los productores de noticias o información. 
El ya añejo caso International News c. Associated Press ${ }^{10}$ (1918) posibilita una mirada que relacione el viejo problema desde las viejas tecnologías y el mercado convencional, donde se planteó en 1918, con el mercado de Internet y las nuevas tecnologías, donde se ha reavivado el mismo mostrando aspectos distintivos.

Recordar que el caso se sustancia entre dos importantes actores productores de información: dos organizaciones mundiales de producción de noticias (recogida y distribución). Una agencia de información propiamente dicha (International News) y una cooperativa internacional de editores de periódicos (Associated Press) ofrecen el mismo servicio diario a distintos periódicos en todo el territorio de Estados Unidos, incluso algunos de ellos son abonados de ambos. El «tipo de negocio» es similar para las dos, aunque la estructura organizativa o «modelo de negocio» difiere. Se resume básicamente en el pago a estas agencias por parte de los periódicos abonados o asociados, en todo el territorio norteamericano, a cambio del servicio de suministro de noticias internacionales por estas organizaciones. Ambas actúan en el mismo mercado (producción de información para Estados Unidos) y obtienen sus ganancias al mismo tiempo (venta diaria de información).

El conflicto que se plantea entre las dos compañías es el siguiente:

«The bill was filed to restrain the pirating of complainant's news by defendant in three ways: First, by bribing employees of newspapers published by complainant's members to furnish Associated Press news to defendant before publication, for transmission by telegraph and telephone to defendant's clients for publication by them; second, by inducing Associated Press members to violate its by-laws and permit defendant to obtain news before publication; and, third, by copying news from bulletin boards and from early editions of complainant's newspapers and selling this, either bodily or after rewriting it, to defendant's customers».

Los dos primeros alegatos fueron descartados por falta de pruebas, y es el tercero el que centra el conflicto: la copia y reproducción sin autorización ni compensación de noticias de los periódicos de la competencia (Associated Press) por parte de International News. Aprovechándose de la diferencia horaria entre la costa este y la oeste de Estados Unidos, International News, mediante instrumentos técnicos como el teléfono y el telégrafo para su pronta transmisión, permitía imprimirlas y venderlas por sus periódicos

${ }^{10}$ International News Service vs. Associated Press, 248 US 215. 
abonados en el otro lado de Estados Unidos, incluso antes que los periódicos de Associated Press. El valor del servicio o clave del modelo de negocio reside en la rapidez o prontitud de la publicación, es decir, en ser el primero en dar la noticia, además de su veracidad y objetividad. Tal valor confiere prestigio y credibilidad al servicio de las agencias (hay que hacer notar que algunos periódicos miembros de Associated Press permitían el acceso a su contenido, incluso antes de su publicación, a International News. Los intereses de la agencia y la de sus miembros no coinciden totalmente).

«The value of the service, and of the news furnished, depends upon the promptness of transmission, as well as upon the accuracy and impartiality of the news; it being essential that the news be transmitted to members or subscribers as early or earlier than similar information can be furnished to competing newspapers by other news services, and that the news furnished by each agency shall not be furnished to newspapers which do not contribute to the expense of gathering it».

Pero el «factor tiempo» presenta peculiaridades en este contencioso que determinan el «valor del servicio» en función de si existen conductas de aprovechamiento injusto del trabajo (noticias) y la reputación ajena (sin citar la fuente), que son, además, conductas contrarias a la leal competencia en el mercado. Lo cual sucede unido al «factor espacio» (diferencia horaria entre costa este-oeste de Estados Unidos), ya que los «instrumentos tecnológicos» del momento, capaces de superar tal diferencia espaciotemporal, permiten la impresión, distribución y publicación de las noticias simultáneamente por ambos competidores en la costa oeste, sin consideración de que Associated Press ha empleado recursos intelectuales, materiales y financieros en la recolección (y puesta a disposición) de las noticias, mientras que International News se ha limitado a «piratearlas».

En definitiva, se trató de determinar 1) si había algún tipo de propiedad en las noticias por parte de quien las recolectaba y elaboraba; 2) si alguna se agotaba al publicarse por el primer periódico al que se le suministró, y 3) si constituía una conducta de competencia desleal en el mercado el uso comercial por un periódico de la competencia de informaciones publicadas previamente por otros periódicos o boletines (en este caso de Associated Press).

International News, aunque entiende que no existe copyright sobre las noticias, defiende, por analogía, una «especie de derecho de propiedad sobre las noticias» que se extingue tras su publicación y que solo subsis- 
te mientras que no se den al público, pues después tal derecho de propiedad se extingue con la primera publicación, y el uso posterior de las mismas por cualquier miembro del público deviene legal (del «common law» al copyright). Sin embargo, cabría añadir, el «secreto» que mantiene el valor de la noticia no casa con el valor del servicio: «dar lo antes posible las noticias frescas». Así, se entendería, en un primer momento, que una vez publicadas su valor decae. Y esto es lo que llevará a la «bot news doctrine» para preservar un tiempo de explotación mientras su valor permanece.

Afirmó, sin embargo, el Tribunal Supremo que, en realidad, se trataba de un problema privado entre las partes, en cuanto a su interés en las noticias tras su primera publicación, como «cuasi-property», en tanto que todavía podían ser objeto de transacción y explotación económica. Y se asumía que ello no afectaba al interés del público (derecho a la información) por parte de las agencias. Se afirmó que las noticias no solo tienen valor de cambio para el que emplea sus recursos empresariales en obtenerlas y distribuirlas en el mercado, sino también para aquel que se apropia indebidamente de ellas después (misappropriation).

El Alto Tribunal fundamentó que es un razonamiento errado (hubo votos particulares disintiendo de esta opinión) afirmar que la postura de Associated Press es contraria a los intereses del público, puesto que International News utilizó «comercialmente» las noticias ya publicadas por Associated Press e incurrió en competencia desleal al competir en el mismo mercado y al mismo tiempo sin haber contribuido en su obtención, considerando los diversos recursos y esfuerzos que requieren. Distinto hubiera sido, aclara el Tribunal, que un lector de un periódico difunda «gratuitamente» el contenido obtenido con cualquier fin que no sea comercial, sin interferir ni competir deslealmente en el mercado:

«Profit from those who have earned it to those who have not; with special advantage to defendant in the competition because of the fact that it is not burdened with any part of the expense of gathering the news. The transaction speaks for itself and a court of equity ought not to hesitate long in characterizing it as unfair competition in business».

Por otra parte, no se puede interpretar que, una vez que las informaciones han sido publicadas, estas quedan «abandonadas» a cualquier uso posterior por cualquier persona. El uso comercial posterior de las mismas restaría a la empresa productora de los justos frutos y beneficios, y, posiblemente, nadie abordaría tal costosa empresa. 
«The contention that the news is abandoned to the public for all purposes when published in the first newspaper is untenable. Abandonment is a question of intent, and the entire organization of the Associated Press negatives such a purpose. The cost of the service would be prohibited if the reward were to be so limited».

Se concluye que no se le concede al demandante (Associated Press) ningún monopolio sobre la reproducción o distribución de noticias, no existiendo copyright, sino solo un tiempo que limite al competidor (International News) la posibilidad de apropiarse de los frutos del trabajo ajeno y explotarlos en otro territorio (costa oeste): la doctrina de la «hot news» y la «missapropiation». El factor tiempo-espacio resulta clave para la protección del negocio. Hay un tiempo de «valor de la noticia» y un territorio donde todavía es posible la explotación, donde todavía tiene valor.

«We are inclined to think a distinction may be drawn between the utilization of tips and the bodily appropriation of news matter, either in its original form or after rewriting and without independent investigation and verification».

También, pues, interesa la distinción que lleva a la cuestión de si el elemento a proteger está en la «forma en que se da la noticia» o en el «contenido de la noticia».

Cuándo se extingue el valor comercial de la noticia pudo estar claro en este viejo caso del «periodismo de papel», con los medios tecnológicos que se disponían al efecto. Pero puede no estar tan claro en el «periodismo digital». Hay que fijarse, como se afirma en el último párrafo citado, que se prohíbe el uso de la noticia en ese «tiempo que existe valor comercial», tanto por su reproducción literal o total como por su sustancia o contenido, incluso reescribiéndolo, tomado de cualquier periódico o soporte (diferente es la situación de utilizar como «tip» la información de otro periódico y, a partir de ahí, realizar investigación propia para generar la propia noticia, lo cual es práctica habitual). Estos firmes parámetros de tiempo-espacio no se mantienen en el soporte digital, como se verá más adelante. El tiempo y el espacio se transforman merced a los clicks y links que convierten la información en viral y global. 


\section{LA DIFÍCIL RELACIÓN ENTRE TÉCNICA Y DERECHOS}

En el caso Agence France Presse c. Google Inc. (2005) ${ }^{11}$ se encuentra, de una parte, una agencia internacional de noticias [Agence France Presse (en adelante, AFP)] y, de la otra, una empresa multinacional de servicios de la sociedad de la información con algunas características absolutamente nuevas (Google Inc.). La AFP demanda a Google por la reproducción sin su autorización en el sitio de Google News de sus noticias, en cuanto que toma sin permiso los titulares de las mismas, sus primeras líneas a modo de sumario y las fotografías que las acompañan. La agencia entiende que, además, la empresa multinacional incurre en competencia directa con ella y sus suscriptores.

«AFP invests a great deal of time and money to acquire its news data to guarantee its top quality international service, which is tailored to the specific needs of clients in each region around the world. AFP's photographs and news stories are original and creative works».

AFP exige el respeto y protección de sus derechos de autor sobre ciertos elementos de la noticia que considera originales y creativos, y solo tangencialmente sugiere las doctrinas de la «hot news» y la «missappropriation», pues Google tiene argumentos suficientes para rechazar la «misappropriation». AFP denuncia el «free-ride» de Google a expensas de su trabajo, publicando sus «hot news» casi a la misma vez.

El modelo de negocio de AFP es, básicamente, semejante al de International News: suministra noticias a sus suscriptores alrededor del mundo, lo cual exige una gran inversión de tiempo y dinero. Asimismo, AFP puede suministrar directamente los materiales a través de los medios técnicos de que disponga en cada zona o mediante el acceso a la base de datos de Internet. AFP licencia el uso de sus fotografías y los clientes acceden a ellas a través de su base de datos. Sin embargo, el suministro directo de noticias es solo para los abonados y las encuentran en la base de datos de la agencia.

El valor del servicio radica en la posibilidad de obtener información mundial y local (noticias, fotografías e imágenes), en diferentes idiomas,

${ }_{11}$ Agence France Presse vs. Google, Inc., case no. 1:05-cv-0056-GK, US District Court for the District of Columbia. 
directamente por Internet, accediendo a su base de datos mediante suscripción o a la carta (mediante pago siempre), tanto a tiempo real como de archivo, ofreciendo el servicio tanto a empresas de todo tipo y medios de comunicación como a particulares e instituciones, desde cualquier parte del mundo y en cualquier momento (bttp://www.afp.com). Google Inc. (www.google.com) es una empresa multinacional norteamericana especializada en servicios y productos relacionados con Internet. Esto incluye tecnología de publicidad on-line, servicios de búsqueda de información, cloud computing, software, dispositivos electrónicos y otras tecnologías. El principal producto de Google es el motor de búsqueda de contenido en Internet del mismo nombre, aunque ofrece también otros servicios.

«24. Defendant also offers a news aggregation service called "Google News" at http://news.google.com, which is not a search service but rather a collection of current news stories (from within the last 30 days) and photographs from over 4,500 news sources. Defendant displays these news stories in categorized pages similar to newspaper sections divided into World, U.S., Business, Sci/Tech, Sports, Entertainment, and Health.

26. The home page for Google News does not look the home page for the Google search engines (e.g. Web, Images, Groups, Froogle, and Local). The typical Google search engine home page starts with a blank with a "Search" button, in which the service's functions are initiated by a user input. Until the search is undertaken there is no information provided. In contrast the Google News home page looks like a traditional newspaper o news aggregator with a multiple column layout».

El modelo de negocio de Google no se puede entender solo mediante Google News Service, pues, de hecho, este servicio es gratuito (como el resto). Para ello hay que atender al conjunto de servicios y actividades de la empresa tecnológica y tener en cuenta que el motor(es) de búsqueda de información en Internet es la clave del negocio, unido a sus soluciones de publicidad on-line, y, conforme a los términos de búsqueda de información, se ofrecen al usuario resultados personalizados por la explotación de sus datos personales, que permiten, a su vez, la personalización y efectividad de la publicidad. Así, es la venta de publicidad la fuente principal de ingresos económicos de Google. Google, al igual que AFP, se constituye en bases de datos de acceso por Internet con diversidad de servicios y productos. Pero mientras que en AFP hay que pagar suscripción o licencia por los servicios y la información, en Google es «aparentemente» gra- 
tis, pues se «conforma» con los datos personales del usuario y consumidor, y con obtener sus beneficios económicos de los anunciantes.

El valor del servicio es doble: para el usuario, la personalización de los contenidos buscados y la satisfacción del interés del usuario con gran variedad de fuentes informativas, y todo ello gratis desde cualquier lugar del mundo y en cualquier momento; para el anunciante, una publicidad personalizada y contextualizada directa al «target» más efectivo.

Los derechos en liza, núcleo del contencioso, son los derechos de autor o copyrights que AFP reclama sobre los titulares de sus noticias, encabezamientos de las mismas y fotografías que se reproducen sin su autorización en Google News, como se ha descrito más arriba. Además, AFP entiende que actuando así, Google News entra en competencia directa no solo con la agencia, sino también con sus suscriptores (medios de comunicación) y licenciatarios. No se puede olvidar que Google toma, fundamentalmente, los materiales de las webs de los periódicos o medios de comunicación suscriptores de AFP (no directamente de su base de datos). Además, se afirma que Google usurpa las relaciones y oportunidades de nuevos negocios, de manera que todo ello resultará en un impacto adverso en el potencial mercado de AFP (aquí de nuevo, los intereses de la agencia no coinciden totalmente con los de sus abonados o licenciatarios, los periódicos, que ven o pueden ver con agrado su presencia en el buscador y el tráfico que les proporciona).

En este caso, casi un siglo después del asunto International News, el elemento tecnológico es dramáticamente diferente: Internet y redes de telecomunicación, software, tecnología digital y bases de datos que almacenan ilimitadamente información, disponibles desde cualquier lugar y a cualquier hora. Ello provoca consecuencias dramáticas también en las formas de recolección, explotación y consumo de la información. Por parte de Google, además, un algoritmo único y extraordinario, protegido como secreto del comercio, permite que los motores de búsqueda y todo el software de la empresa tecnológica accedan a toda la información del mundo para su organización, acceso y consumo en Internet. Cuando Google toma la información de AFP y/o de sus suscriptores, lo hace casi inmediatamente después de hecha pública, pero se ha hecho de una sola vez en todas partes (el valor de actualidad se ha consumado). Los factores tiempo-espacio han quedado reducidos en la red a un simple «click», de manera que ya no son pertinentes para identificar o delimitar mercados, es decir, si en el caso International News los elementos tiempo-espacio permitían ponderar si existía «valor comercial de la noticia», aquí ya no son pertinentes al efecto. En este caso, parece que las posibilidades de «nuevas explotaciones de las noticias ya difundidas» vienen dadas por 
las utilidades que ofrezca la tecnología o software, es decir, el «valor comercial de la noticia» subsiste en tanto existe una herramienta, instrumento o manera capaz de generar otra explotación o utilidad. Aquí, Google dispone, por las habilidades de su «mágico» algoritmo, de un software capaz de recolectar y agregar las noticias mundiales ya publicadas en otras webs y reutilizarlas en Google News y después en los servicios de búsqueda de Google, donde se genera y exhibe la publicidad. Y aún más, puede seguir reutilizando la información en otros servicios, como Google Analitics, cadena de difusión de las mismas noticias cuya explotación no siempre redunda en beneficios materiales, sino también en inmateriales, es decir, en visibilidad, prestigio, datos de tráfico, marca, etc. En definitiva, la viralidad y las posibilidades de reutilización de la información y la explotación de los datos en que consiste confieren nuevo «valor» al servicio.

De tal manera que tanto la información de AFP como la de Google es accesible vía Internet, sin límites de tiempo y/o espacio, y que estos elementos (tiempo-espacio) ya no resultan operativos para separar o delimitar mercados y competencia como ocurría en el caso International News. Pero la diferencia entre AFP y Google es la tecnología de Google (su algoritmo), que tiene la capacidad de acceder a todos los sitios y webs de Internet, obtener su contenido, datos e información, y utilizarla de muy diferentes maneras. Google News es una de ellas. Así, todos pueden acceder a todo en Google y, a su vez, Google accede a todo de todos, recolectando información de todo tipo, susceptible de muchos usos y explotaciones. Lo cual le da una ventaja competitiva extraordinaria que reside en su novedosa tecnología, que funciona con base en su algoritmo.

También Google, en desacuerdo con las reclamaciones de AFP, rechaza que vulnere derechos de autor y que incurra en competencia desleal.

En definitiva, niega que vulnere los derechos de autor de AFP al usar como links los titulares, reproducir el primer fragmento de la noticia y la huella fotográfica: se trata de un index de links, a libre disposición del usuario. Y tampoco incurre en competencia desleal al dirigir a los usuarios, saliendo de Google News, hasta la originaria web del editor, donde se encuentra toda la noticia y la fotografía propiamente. Actuando así, tampoco daña el mercado de AFP de ninguna manera, pues lo que realmente hace es atraer nuevos lectores y tráfico a esa web.

Asociamos este conflicto de derechos de autor con otro más reciente, caso Svensson (2014) ${ }^{12}$, en el que el Tribunal de la Unión Europea afirma

12 STJEU de 13 de febrero de 2014, asunto C-466/12, Nils Svensson et al. 
que una «lista o índice de links» es una «puesta a disposición del público», pues propicia el elemento del «acto comunicación» a un público potencial (considerandos 18, 19 y 20). Sin embargo, en ese caso no existe «comunicación al público», dado que el lugar al que enlazan y se exhibe al presionar el link es un sitio abierto, es decir, de acceso libre. Acceder a través de la página de links de la empresa Svensson no añade «publico nuevo» que no considerara el titular o autor de los derechos al autorizar la comunicación al público en el sitio original (con las salvedades que se señalan). De manera que AFP acierta en reclamar derechos de autor respecto a elementos concretos reproducidos materialmente en la página de Google News, dado que, de haber reclamado derechos por el solo hecho del despliegue del índice de links, podría haber fracasado en sus pretensiones. Y es que, salvo excepciones determinadas, en el mismo caso Svensson (que esté en la memoria oculta del buscador y ya no se encuentre en la web del periódico) Google enlaza a las webs originales que son de libre acceso, según alegaciones, y aunque pueda aportar «nuevo tráfico de datos» no aporta, conforme a esta jurisprudencia, «público nuevo» (conforme al Tribunal Europeo, entonces, no vulneraría derechos de autor).

En la asunto Google Inc., Google desmonta jurídicamente las acusaciones y asegura que en los elementos citados o no existe copyright o, si existe, su conducta está protegida por la «fair use», dada la escasa cantidad utilizada y el «uso transformativo» hecho de la misma. También niega que haya alterado ilícitamente los CMI (Copyright Management Information) al acceder a la fuente original, sencillamente porque no reproduce.

En el caso Infipaq International A/AS c. Danske Dagblades Forening (DDF) (2009) ${ }^{13}$ las partes son europeas y la jurisdicción y el Derecho aplicable también, y se sustancia ante el Tribunal de Justicia de la Unión Europea (en adelante, TJUE). Se trata de una cuestión prejudicial que se plantea ante el Alto Tribunal Europeo y trae causa de un litigio danés. DDF estima que Infopaq infringe los derechos de autor de sus representados y lo demanda por vulneración de derechos de autor, que recurre la decisión del tribunal danés.

Una de las partes, la demandante (Infopaq), lleva a cabo el siguiente negocio: Infopaq desarrolla una actividad de seguimiento y análisis de medios de comunicación impresos cuyo objetivo principal es la elaboración de resúmenes de artículos seleccionados procedentes de diarios y otras

${ }_{13}$ STJEU de 19 de julio de 2009, asunto C-5/08, Infopaq International A/S vs. Danske Dagblades Forening. 
publicaciones periódicas danesas. Los artículos se seleccionan mediante un «procedimiento de recopilación de datos» en función de determinados criterios temáticos convenidos con los clientes. Los resúmenes se envían a estos por correo electrónico. El valor del servicio reside en despachar a cada cliente, individualizadamente, unos contenidos muy detallados y analizados de la prensa escrita en general conforme a unos interese personalizados (monitorizar, seguir, leer la prensa para la selección de artículos conforme a criterios, y, tras el análisis, presentar los resúmenes para fines propios a cada cliente por email).

La otra parte, una asociación profesional de editores de prensa diaria (DDF) a los cuales representa y asiste en defensa de sus derechos de autor.

La clave de la disputa se encuentra en el procedimiento de recopilación de datos que Infopaq utiliza para la elaboración final de los extractos de artículos: mitad automático/mitad manual. El Alto Tribunal debe aclarar si, conforme a la Directiva europea, existe una reproducción parcial de una obra (en las once palabras que constituye el extracto, almacenado en el ordenador e impreso en papel), y, por tanto, sujeta a autorización, y si, aun habiéndola, queda exenta al ser considerada temporal y transitoria (art. 5.1 de la Directiva), por razones de transmisión tecnológica.

El procedimiento empleado por Infopaq de recopilación de los datos que utilizan sin necesidad de recabar el consentimiento de la DDF ni de sus miembros, como señala la sentencia, comprende cinco fases, de las cuales DDF estima que contienen cuatro actos diferentes de reproducción de los artículos de prensa.

El tribunal danés desestima la demanda de Infopaq, que interpone recurso de apelación ante el tribunal superior correspondiente. Este tribunal suspende el procedimiento y plantea al TJUE varias cuestiones prejudiciales. Se plantean numerosas preguntas, pero con buen criterio el TJUE las reduce en esencia a las dos siguientes:

1. ¿Constituye un acto de reproducción («reproduction in part»), sujeto a autorización de los titulares, el almacenamiento en el ordenador y posterior impresión en papel del extracto de once palabras del artículo? (puesto que los actos de las primeras fases son reproducción, aunque exentas como parte de un proceso tecnológico transitorio).

El TJUE responde a esta cuestión estableciendo que hay reproducción en el citado extracto, parcial y no de la obra al completo, y requerirá la solicitud de autorización a los titulares si ese extracto, por sí mismo, contiene algún elemento que permita expresar la creación intelectual del autor (if the extract contains an element of the work which, as such, 
expresses the authors's own creation). El tribunal determina que ese juicio corresponderá al tribunal danés que plantea la cuestión prejudicial. En los considerandos, el TJUE ha reconocido la propiedad intelectual de los artículos de periódicos.

2. ¿Constituyen los actos de reproducción utilizados por Infopaq en su procedimiento de recopilación de datos actos de reproducción provisional contenidos en la excepción legal del art. 5, apartado 1, de la Directiva 2001/29 y, por tanto, no sujetos a autorización? (que debe ser interpretado en relación con el art. 5.5 de la Directiva, «no perjudicar la normal explotación de la obra»).

Se está ante un caso de doble naturaleza: soporte papel/soporte digital; proceso manual con intervención humana/proceso tecnológico de forma automática. Y también un caso donde son varios derechos los que confluyen en un mismo acto: derecho de autor (copyright), derecho sobre las base datos, protección datos y derecho a la información. Aunque no todos estos derechos están invocados expresamente, se manifiestan claramente en los razonamientos de la sentencia. El proceso de recopilación de datos deviene al final del mismo, como resultado, en una «información» susceptible de protección por «copyright» y en un ejercicio del derecho a la información: se comienza el acceso a los medios de comunicación de manera manual, se registran en la base de datos y se leen de forma humana, y después, mediante el proceso electrónico, se hace una búsqueda por palabras que finalmente, al tomar un extracto, que se almacena, aunque mínimo, es susceptible de derechos de autor. Extracto que, unido a los datos que lo identifican (considerando 21): fecha, nombre del periódico, página, sección, porcentaje de aparición de la palabra y las «once palabras» que se toman literales de antes y después del término de búsqueda donde aparece, permite afirmar que representa una reproducción parcial, al traer «la originalidad total» a la parte pequeña reproducida.

El elemento técnico permite aquí contrastar cómo, dependiendo de uno u otro (analógico/digital), tiene un claro impacto sobre los derechos, su ejercicio y la responsabilidad que se sigue del mismo. De manera que, mientras se trata de soporte papel y de un proceso manual con intervención humana, el derecho de reproducción se reconoce, exigiendo el necesario acto de autorización por parte del titular/es para ejercerlo. Sin embargo, cuando se trata del proceso tecnológico (automático digital), se asume que no hay conocimiento e intervención humana y se aceptan las reproducciones como transitorias y accesorias, sin un valor económico aislado por ellas mismas, y, por tanto, como «no reproducciones». Igual- 
mente, en el considerando 33 se afirma que los «datos de la información» pueden ser extraídos por el intermediario de la comunicación en proceso tecnológico siempre que no los modifique. Infopaq, en el proceso de recopilación y elaboración, da lugar a un proceso de tratamiento de datos, que son datos de información y datos personales, que después se comunican por email a los clientes comercialmente. Hay también un ejercicio de derecho a la información que satisface a los clientes, aunque con finalidad comercial, a partir de los periódicos ya publicados. Cabría preguntarse si se está, por tanto, dentro del ámbito del derecho a la información, prevaleciendo sobre el derecho de autor, o si se trata del «valor comercial de la noticia» que, merced a la técnica y a esta ingeniosa manera de tratarla, ofrece este nuevo mercado (reutilización y explotación de las informaciones/datos) en el que el factor tiempo, la actualidad de la noticia («hot news»), no es el valor de apropiación, sino que el valor vendría dado por los datos que contienen las publicaciones, el cual es tomado por Infopaq para sí mismo y para sus clientes, que después lo utilizarán con distintas finalidades (estrategias de negocio, marketing, estudios, etc.). Pero a nadie se le escapa que Infopaq «puede» utilizar todos los datos y referencias para construir y nutrir su base de datos electrónica (hay que recordar que los extractos quedan almacenados y hasta impresos en papel, sin seguridad de su destrucción posterior). La reutilización de la información y la explotación de los datos es un nuevo mercado. Este «negocio de los datos» tiene muchas y variadas posibilidades; solo hay que mirar al gigante Google que se sostiene en los «fabulosos pies de los datos».

Podría decirse, al menos en principio y aparentemente, que Infopaq no compite con los primeros (los diarios), pero sí se da enriquecimiento injusto, pues toman los datos e información de la «cantera de la prensa», aunque después requiera mucho trabajo la transformación de los contenidos (excepción incluso al copyright), salvo que se tenga una solución técnica innovadora, como el algoritmo de Google. Aquí el «big data analitics» y su explotación se están mostrando como incipientes negocios.

En definitiva, en papel hay derecho; no, sin embargo, en el proceso digital de la transmisión. En papel no sería posible, a efectos de mercado, un uso de la información de esa manera. En efecto, se está produciendo un nuevo «valor comercial de la noticia» merced a la tecnología y las posibilidades que ofrece, aunque ello pueda suponer también un tratamiento de datos, con las implicaciones jurídicas correspondientes.

A continuación dos casos, uno de un órgano judicial de menor jerarquía y el otro del Tribunal Supremo, en jurisdicción y Derecho norteame- 
ricano, que muestran, nítidamente, un progresivo cambio de concepción de los modelos de negocio de noticias e información.

New York Times Company, Inc., et al., Petitioners c. Jonathan Tasini et al. (2001) ${ }^{14}$

Un nuevo caso en el que los copyrights son la causa de un litigio en el que se encuentran como partes: periodistas free-lance, encabezado por J. Tasini, enfrentados a periódicos impresos (dos diarios y una revista), estando al frente New York Times (www.nytimes.com), y a la empresa propietaria y gestora de las bases de datos Lexis/Nexis (se unen otras instituciones de la misma naturaleza).

Las empresas editoras de los periódicos tienen en ese momento básicamente la estructura y el modelo de negocio tradicional: provén información y reciben los ingresos de la venta de sus ejemplares, suscripciones y venta de publicidad. Las ediciones digitales (New York Times) van a ir modificando con el tiempo sus modelos con las nuevas posibilidades online de publicidad (tráfico de datos) y la modificación de la venta y suscripción de ejemplares por la «pay wall». Licenciar a las bases de datos la reproducción de artículos parece una estrategia más de los periódicos en busca de nuevas formas de ingresos para superar la crisis de sus modelos convencionales (las otras publicaciones implicadas incluso licencian a universidades). La empresa propietaria de Nexis/Lexis gestiona las bases de datos electrónicas que almacenan documentos y textos de todo tipo para su comercialización mediante licencias. Son agregadores electrónicos de contenidos (the Lexis/Nexis central discs or UMI CD-ROMS) y proveen documentación tan detallada como el usuario requiera. Nexis contiene artículos de cientos de periódicos que se han ido incrementando con los años. No contiene ni publicidad ni fotografías: «Nexis does not contain pictures or advertisements, and it does not reproduce the original print publication's formatting features such as hedline size, page placement or location of continuation pages». Sus ingresos provienen de las licencias por sus contenidos.

La disputa surge cuando los editores de estos periódicos acuerdan con la empresa que explota bases de datos electrónicas (Lexis/Nexis), sin el consentimiento de los free-lancers, la puesta a disposición y comercialización de los artículos de los periódicos, incluidos los artículos de estos periodistas. Cuando el usuario accede a los artículos en la base de datos, estos se presentan aislados, fuera del contexto del periódico en el que se

${ }^{14}$ New York. Times Company, Inc., et al., vs. Tasini et. al. 533 US 483121 S. Ct. 2381. 
encontraban originariamente. Las empresas editoras de estos periódicos (The Times, Newsday y Time), como titulares de la obra colectiva que es la publicación periódica, han registrado los correspondientes derechos. Igualmente, estos free-lancers han registrado cada uno de los copyrights correspondientes a cada artículo. La relación de estos periodistas con las empresas editoras se hace como contratistas independientes, y en los respectivos contratos no figura el consentimiento de los mismos para la explotación de sus trabajos en bases de datos, solo para la publicación con la que contribuyen a la edición de los periódicos.

Los periodistas free-lancers reclaman sus derechos de autor, alegando que han sido vulnerados al incluir sus artículos periodísticos en las bases de datos para su comercialización sin su permiso. Las empresas editoras afirman sus derechos de reproducción y distribución como titulares de la obra colectiva que es el periódico.

El editor, pues, tiene derechos sobre el «todo» de la obra colectiva (collective work) que es el periódico, pero no sobre las partes (los artículos), concretamente cuando han sido contratados free-lance y no existe una relación laboral («Works made for hired»). Como se hace ver en la nota 7 , los editores no reclaman que los artículos en cuestión sean «work made for hire. 17 U.S.C. $\$ 201(b)$. As to such Works, the employer or person for whom a work ws prepared is treated as the author». El derecho de reproducción y distribución de los editores respecto a las contribuciones independientes abarca solo la posibilidad de la primera publicación, las posibles revisiones de las mismas o más tarde el uso de la obra dentro del espectro de publicación habitual del periódico. Conforme a la decisión del Tribunal Supremo, la autorización y compensación al free-lancer debería haber precedido antes de acordar licencia alguna con las bases de datos. En definitiva, el autor free-lance es libre de vender su obra en el mercado, salvo pacto en contrario, al mejor precio.

El punto controvertido fue, pues, demostrar si en la base de datos se reproducía el «todo» (la obra colectiva) o si se trataba de alguna «revisión» de la misma, de tal manera que en ese caso los derechos recaían sobre el titular del periódico (el editor). Mientras que, si la presentación y explotación de los artículos se hacía aisladamente, como piezas individuales, sin conexión al contexto total, entonces el free-lancer mantenía sus derechos intactos. Como se describe y demuestra en la decisión del Alto Tribunal, los artículos se presentan al usuario sin ningún «link» que lleve a la obra original o sin reproducir la publicación original total donde se encuentran. 
Tampoco se aprecia en el examen que la «collective work» conlleve revisión alguna en su tratamiento en la base de datos.

Desde el punto de vista técnico, se encuentran algunas semejanzas en el funcionamiento de estas bases de datos con las de Google, salvo que Google es un servicio en Internet abierto y que su algoritmo permite habilidades que aquí no se encuentran. Llama la atención que una función técnica, el «link», podría haber cambiado el veredicto final de la sentencia a favor de los editores (la reproducción «total» de la «collective work» es facultad de los editores, a diferencia de «articles retrieved by users provide no links to other articles appearing in the original print publication»). Estos agregadores electrónicos que son las bases de datos tienen una capacidad infinita de almacenar información general y especializada, organizarla y recuperarla (que les distingue de las bibliotecas de «papel») desde cualquier ordenador del mundo en cualquier momento, vía Internet, siempre que se tenga una licencia de uso. En esta ocasión el valor de los contenidos de los periódicos no viene dado por el tiempo (actualidad) o espacio (disponible o interesante en un lugar concreto), sino por la «recolección» de documentos para uso diverso (estudio, negocios, enseñanza e investigación, marketing, etc.). Derecho de recolección y reproducción que pagan las bases de datos y del se benefician los periódicos. Aunque, se podría pensar, es un servicio que bien podrían ofrecer las mismas empresas editoras maximizando su esfuerzo e inversión o derechos (licenciar sus obras) que podrían ejercer directamente los periodistas y/o autores en general en el mundo digital de Internet. Lo que aquí sí se muestra claro es que un nuevo uso y/o un nuevo medio donde se publique su trabajo es una nueva remuneración para los periodistas. Y también parece que soluciones técnicas como los motores de búsqueda (especialmente Google) han esquilmado considerablemente el modelo de negocio de las bases de datos, de los periodistas (por los links) y de los mismos periódicos, pues son capaces de ofrecer «casi» (no cubren todos los periódicos ni son tan especializados) todos esos servicios al público «gratis».

El Tribunal Supremo dictó que los editores y los titulares de las bases de datos vulneraban los derechos de los free-lancers. Resulta revelador cómo la llamada «tasa Google» en la vigente Ley de Propiedad Intelectual compensa únicamente al editor. Sin embargo, en la nueva Directiva de derechos de autor se evoluciona para que autores y medios de comunicación compartan los beneficios de nuevas explotaciones ${ }^{15}$.

15 Directiva (UE) 2019/790 del Parlamento Europeo y del Consejo, de 17 de abril, sobre los derechos de autor y derechos afines en el mercado único digital y por la que se 
Tasini c. AOL, Inc. (Huffington Post) (2012) ${ }^{16}$

En este caso no se está ante el Tribunal Supremo ni en él se disputan los copyrights, tampoco cuestión alguna de competencia desleal. Este es un novedoso caso que entra de lleno en la dinámica del «periodismo digital» y los nuevos modelos de negocio en la red, y donde los «periodistas bloggers» (Tasini y otros) reclaman compensación económica por enriquecimiento injusto («unjust enrichment») y negocios engañosos («deceptive business») al agregador digital de contenidos AOL (y Huffington Post) a expensas de sus colaboraciones.

El conflicto:

«The plaintiffs, Jonathan Tasini (and others) bring this proposed class action under the common law doctrine of unjust enrichment and New York General Business Law. The plaintiffs have sued AOL.Inc. The HuffingtonPost.com.Inc, Arianna Huffington ("Huffington"), and Kenneth Lerer ("Lerer") (collectively "the defendants"), alleging that the defendants unjustly and deceptively denied the plaintiffs compensation for submitting content to and promoting content on The Huffington Post (www.thehuffingtonpost. com), a website owned and operated by the defendants».

Las partes:

«The Huffington Post launched its www.huffingtonpost.com website as a for profit enterprise on May 9 (2005). The Huffington Post was ostensibly created by defendants Huffington and Lever, although the proper attribution of The Huffington Post's creation is subject to ongoing litigation. The website has become quite popular, receiving more than 26 million unique visitors per month as of January. The website provides a mix of content that is written by paid staff members, collected from other websites, or submitted by unpaid bloggers who have been selected or recruited to blog for the website. The named plaintiffs and prospective class members are members of the last group: the website's unpaid content providers. The majority of these content providers are "professional" or quasi-professional writers».

El problema surge cuando Huffington Post Web es vendida a AOL por una sustanciosa cantidad de dinero y los bloggers reclaman su parte, pues el éxito de la web se debe en gran medida a su trabajo, su prestigio y el trá-

modifican las Directivas 96/9/CE y 2001/29/CE, art. 15. Vid. la llamada «Tasa Google» en Ley 21/2014, de 4 de noviembre, de Propiedad Intelectual, art. 32.2.

${ }^{16}$ Tasini vs. I. AOL, 851 F. Supp. 2d 734-Dist.Court, SD New York, 2012. 
fico de visitantes que atraen por sus colaboraciones en la web, lo que eleva los ingresos por publicidad.

El modelo de negocio de Huffington Post resulta, respecto a los anteriores, muy novedoso: se trata de un agregador de agregadores de contenido. Solo una mínima parte es creada por el mismo medio, el resto es libremente agregado y gratis. Por tanto, el coste de producción es mínimo y los ingresos generados por la («target») publicidad son muy sustanciosos, debido al tráfico de datos de los visitantes que genera tanto la publicación como, especialmente, sus bloggers, que la promueven a través de sus propios blogs, webs, redes sociales, sms, emails, etcétera.

«The Huffington Post encourages the bloggers to promote their own submissions via their social networks such as by sending emails, sharing their posts on Facebookor MySpace, responding to reader comments, and contacting other blogs. As a result, the Complaint alleges that The Huffington Post gains more both in terms of exposure and monetary value from the unpaid submissions than do the authors. From its inception The Huffington Post has generated revenue by, among other things, selling advertising targeted towards visitors to the website. Advertising revenues increase in proportion to the amount of page views a website receives, which in turn is a function of the quality of the content provided, as well as the website's ability to attract visitors either through its own marketing or via the social networks of others».

El valor de su servicio radica en que Huffington Post «gana más, tanto en términos de dinero como de visibilidad y exposición, de las colaboraciones que no son pagadas que de los contenidos propios que crean los autores de la web». Es decir, el valor, en primer lugar, es el prestigio mismo de la web (por lo que se hace atractiva y valiosa para los colaboradores), y después, la visibilidad, la exposición y la promoción, en una especie de simbiosis, tanto de la web como de sus colaboradores (cuanto más prestigio, más visibilidad), que viene dada por la máxima difusión posible, en una continuada cadena de difusiones de los mismos contenidos (gratis) en diferentes espacios y medios (la propia web, los motores de búsqueda, blogs, redes sociales, otros media, emails, etc.). Cuanta más difusión y/o prestigio, más visibilidad, más promoción y más prestigio, y, por tanto, más tráfico de datos, que procura más publicidad de mayor valor y más ingresos. En definitiva, la viralidad es el valor de la información, consecuencia de los clicks y los links.

No se reclaman derechos de autor ni defensa por competencia desleal; de hecho, se anima a publicar en todos los medios y en todas partes, 
sin consideración de competencia. Lo que se reclama aquí, según la parte demandada, es una compensación económica por enriquecimiento injusto y prácticas engañosas, que se producen cuando Huffington Post es vendido a AOL y los bloggers no reciben compensación económica alguna de la lucrativa transacción; dinero que solo engrosa la empresa.

Sin embargo, los demandantes fallan en demostrar tanto el enriquecimiento injusto como las prácticas engañosas de los negocios de AOL. No hay enriquecimiento injusto porque ellos ya han sido pagados según contrataron: con exposición, visibilidad y el prestigio de aparecer en Huffington Post, pero no con dinero. De hecho, se les llega a afear por querer romper las reglas del juego, «los términos de contratación». Sin embargo, Tasini acordó las reglas del juego con Huffington Post, no con AOL. Aun así, los bloggers tienen que aceptar un cambio que nunca pactaron y sobre el que nunca fueron consultados.

Todas estas razones son rechazadas por una razón principalmente: nada de lo que figura en el contrato puede hacer pensar a los demandantes que pueden tener estas expectativas o ignorar que es una empresa comercial, lo que no obsta para desarrollar una plataforma «como un foro libre de ideas». Tampoco el juez encuentra actos materiales de los demandados que incurran en las conductas descritas por los demandantes. Tasini y el resto de los bloggers no pueden ser calificados legalmente como «consumidores» en relación con el Huffington Post y, en consecuencia, no se detecta perjuicio alguno.

Sin embargo, en otro caso en el mismo año, NY Times Co. c. AOL (2012), Huffington Post va a tener la oportunidad de aprender la lección; poniéndose de relieve, por contraste, las razones de los bloggers y su valor para quienes los albergan, más allá de la visibilidad y el posible prestigio que reciben de la «web madre».

La importancia y el valor de los blogs y los bloggers como «brand trademark» y su impacto en los anunciantes, lectores y en el mismo periódico en el que aparecen, podrían trasladarse al caso de Tasini para «reexaminar»si estos, como parte de la web que es vendida, no merecen alguna compensación, aunque solo fuera porque el cambio de empresa puede afectar al aura del blogger, su marca y su «brand», confundiendo a lectores y anunciantes, y perjudicándole, finalmente, en su prestigio (aura). La lectura de las razones arriba expuestas deben leerse en las dos direcciones: empresa-blogger. La lección parece aprendida si observamos la presencia de los periódicos digitales en las redes sociales (Facebook, Twitter), con las que alcanzan 
acuerdos y no solo comparten tráfico (en ambas direcciones) y visibilidad, sino ingresos por publicidad.

En el caso expuesto, aunque los autores pueden tener razones a su favor (y las tienen), la fundamentación legal ha sido desafortunada.

\section{TODA LA INFORMACIÓN SON DATOS: LA CRISIS DE PRIVACIDAD}

El derecho a la protección de datos personales (privacy) y el derecho a la libertad de información se encuentran a veces en situaciones de tensión, llamando a una armonización que requiere la preferencia del uno sobre el otro. Si bien esto ya ocurría antes de la realidad digital y las nuevas tecnologías, lo cierto es que en el contexto Internet esta armonización se vuelve más complicada y ambigua, ya que el acceso a la información requiere datos y los datos son el tejido mismo de la información, la cual a veces también está protegida por la propiedad intelectual. La posibilidad de llegar a la identidad a partir de muy pocos datos ${ }^{17}$, haciendo casi imposible el anonimato en la red, ha causado lo que podemos llamar una «crisis de privacidad», con importantes consecuencias en la sociedad democrática. La confluencia de derechos fundamentales en la navegación (algunos de nueva factura) convierte a la red en una constelación de difícil armonización, si se «piensa» en términos tradicionales. Modelos de negocio de información que emplean nuevos soportes de comercialización, los móviles telefónicos (en el próximo caso) o negocios que «reutilizan» las informaciones a partir de los motores de búsquedas (Google), por ejemplo, plantean cuestiones nuevas. Una mirada desde unos casos jurisprudenciales (implicando unos soportes y tecnologías) a otros de tecnologías de última generación, muestra cambios que exigen mejores respuestas.

Desde el año 2008, donde se fecha el caso Satamedia, al 2014, en el que se pronuncia el Tribunal de Justicia Europeo sobre la cuestión prejudicial del caso que enfrenta a la Agencia de Protección de Datos española y Google, es posible observar un gigantesco cambio de concepción en la protección de datos y de la información.

${ }^{17}$ H. Nissebaum y S. Barocas, «Big Data's End Run around Anonymity and Consent», en J. Lane et al (eds.), Privacy, Big Data, and The Public Good: Frameworks for Engagement, New York, Cambridge University Press, 2014, pp. 44-76. 


\section{Tietosuojavaltuutetuu c. Satakunnan Markkinaporssi} oy and Satamedia oy $(2008)^{18}$

Dicha petición se presentó en el marco de un litigio entre, por una parte, el Tietosuojavaltuutettu (mediador encargado de la protección de datos) y, por otra, la Tietosuojalautakunta (comisión de protección de datos) en relación con actividades de tratamiento de datos personales llevadas a cabo por las sociedades Satakunnan Markkinapörssi Oy (en lo sucesivo, «Markkinapörssi») y Satamedia Oy (en lo sucesivo, «Satamedia»).

Estas dos sociedades con ánimo de lucro basan su negocio: una, en la toma de datos fiscales públicos de documentos oficiales de las Administraciones Públicas finlandesas para su publicación en un medio de comunicación social convencional (un periódico en soporte papel), y la otra, en la toma de los datos personales del periódico para su posterior difusión y comercialización a través de los teléfonos móviles, mediante mensajes SMS, a petición del usuario, por el precio de dos euros por mensaje.

La estructura del modelo de negocio se puede describir, siguiendo lo expuesto en la resolución, de esta manera: el acceso libre por una empresa a fuentes de información pública (documentos administrativos), de donde se toman datos personales de carácter fiscal y se publican en un periódico, y sirviéndose de otra empresa, con los mismos titulares, toman y reutilizan los mismos datos personales, que se han hecho públicos en el periódico (fuente pública), para su comercialización, habiendo establecido un acuerdo con una empresa de telefonía mediante un servicio de mensajes de texto. Llama la atención que la actividad, tanto del periódico como del servicio de mensajes de telefonía móvil, tiene como única finalidad la publicación y difusión de datos personales. El modelo papel/digital se ha visto también en el caso Infopaq, aunque referido a derechos de propiedad intelectual (en un soporte existía el derecho, en el otro no).

El conflicto surge cuando: «A raíz de denuncias de particulares que alegaban la violación de su intimidad, el Tietosuojavaltuutettu encargado de investigar las actividades de Markkinapörssi y Satamedia solicitó el 10 de marzo de 2004 a la Tietosuojalautakunta que prohibiera a estas últimas continuar las actividades relativas al tratamiento de datos personales controvertido». Por tanto, los derechos en liza son la intimidad o privacidad de las personas (protección de datos) y el derecho a la libertad de información. Y aunque no se duda del carácter público de los datos fiscales y de

${ }^{18}$ STJUE de 16 de diciembre de 2008, asunto C-73/07, Tietosuojavaltuutetu and Satakunnan Markkinaporssi Oy, Satamedia Oy. 
la legalidad de su transmisión, la pregunta más importante, admitido que existe en todo ello «tratamiento de datos personales realizado con fines exclusivamente periodísticos», en el sentido del art. 9 de la Directiva, es si «¿debe interpretarse el art. 17 de la Directiva [...], en relación con los principios y la finalidad de la misma, en el sentido de que se opone a la publicación de datos que se han recogido con fines periodísticos y a su cesión con fines comerciales? [...] ¿Puede interpretarse la Directiva [...] en el sentido de que quedan totalmente excluidos de su ámbito de aplicación los ficheros nominativos que únicamente contienen información ya publicada tal cual en los medios de comunicación?».

La sentencia deja claro que los datos de las fuentes públicas (datos recogidos de los medios de comunicación) se someten a la Directiva, luego su posible cesión y uso posterior debe cumplir con los principios y normas de la misma. La legalidad del tratamiento de los datos y su publicación con fines periodísticos en Veroporssi, un periódico en soporte papel (se aplica la excepción de finalidad informativa), es clara, es decir, para un medio de comunicación social convencional (soporte papel). No parece clara la aplicación de la «finalidad informativa o periodística» cuando se trata de su cesión para su «comercialización» a través de mensajes de texto en los teléfonos móviles, a petición del usuario. El Tribunal contesta así:

«Resulta interesante el concepto amplio que se da de "actividad periodística", con independencia del soporte (ya se dijo en el caso Lindquist que la libertad de expresión no depende del soporte, fundamento 77), y que no queda circunscrita a los modelos y medios de comunicación convencionales. Es la "intención o finalidad" o naturaleza de la actividad misma, y no el etiquetado del medio donde se incluye (diferencia con el caso Google, derecho al olvido, en el que la finalidad comercial del buscador se antepone a su actividad informativa, según el tribunal). Esta sentencia europea, muy anterior en el tiempo a la del caso Sorrel en Estados Unidos, ya sienta que la difusión de datos puede constituir actividad informativa o periodística, es decir, forma parte de la libertad de información y expresión, que no está limitada a los medios de comunicación convencionales. Y, por supuesto, el carácter comercial y crematístico no empece para la calificación de "actividad periodística o informativa". Como bien dice la resolución, "incluso un cierto éxito comercial es necesario para mantener el periodismo profesional"».

Evidentemente, estas conclusiones chocan, de alguna manera, con la distinción y el tratamiento diferente que hace este mismo tribunal en el 
caso del «derecho al olvido», que se verá seguidamente, entre las fuentes de información periodísticas (medios de comunicación) y la fuentes de información que son los motores de búsqueda, en tanto que las «excepciones o exenciones» (Directiva de datos o Directiva de derechos de autor) que se aplican a unas pueden no aplicarse a las otras respecto a la misma información, según aparezca en uno u otro, afectando a los datos personales y a la información en general que en ellos se encuentra. En Estados Unidos, el caso Sorrell (que se encuentra más abajo) también entiende que la difusión de datos personales es libertad de información y expresión, incluso aunque tales mensajes sean de carácter comercial (publicidad y marketing).

Los distintos soportes son relevantes por los factores tiempo-espacio en el modelo de negocio. Mientras que el periódico es de carácter regional y de periodicidad anual, los mensajes de texto de los móviles se solicitan por los usuarios a petición propia, especificando el nombre de la persona de la que se solicitan los datos, desde cualquier parte y en cualquier momento. Mientras que en el medio papel solo se dan los datos de cada zona, en el móvil se accede a los datos de todas las regiones y de todos los ciudadanos, si se solicita por el usuario, por el precio de dos euros por mensaje. En detrimento de la protección de datos, en la edición periódica quedaban expuestos todos los nombres y datos en esa región, aun sin ser solicitados. Aunque por el móvil se evita esa exposición generalizada de datos personales, es, sin embargo, más fácil su transmisión y falta de control. Obviamente, la conjugación periódico/teléfono maximiza los rendimientos económicos; publicando los mismos «materiales» reutilizables a través de otro soporte o instrumento de comunicación también se maximizan los riesgos en los datos. Así, cabe pensar que el coste económico limita las peticiones y el conocimiento de datos que son, aunque públicos, de carácter privado, pues revelan mucho de cada persona. El dar más publicidad a lo ya público puede tener consecuencias en la privacidad de las personas. Es decir, los datos fiscales constan en documentos públicos de libre acceso, en la Administración correspondiente, incluso publicados en un periódico regional anualmente, pero el teléfono móvil les confiere una publicidad más amplia en tiempo-espacio y personas (público) (the value of the service is the convenience of getting easily very useful and valuble public data). La tecnología se muestra, una vez más, relevante en el modelo de negocio y en las consecuencias sobre la privacidad o protección de datos. 


\section{Google Spain, S. L.; Google Inc. c. Agencia Española de Protección} de Datos y Mario Costejo González (2014) ${ }^{19}$

$\mathrm{El}$ asunto (entre un ciudadano particular y la empresa Google) es resumido en la sentencia de la cuestión prejudicial en el punto 15:

«Mediante esta reclamación, el Sr. Costejo González solicitaba, por un lado, que se exigiese a La Vanguardia eliminar o modificar la publicación para que no apareciesen sus datos personales o utilizar las herramientas facilitadas por los motores de búsqueda para proteger estos datos. Por otro lado, solicitaba que se exigiese a Google Spain o a Google Inc. que eliminaran u ocultaran sus datos personales para que dejaran de incluirse en sus resultados de búsqueda y dejaran de estar ligados a los enlaces de La Vanguardia. En este marco, el Sr. Costejo González afirmaba que el embargo al que se vio sometido en su día estaba totalmente solucionado y resuelto desde hace años y carecía de relevancia actualmente».

Aunque es la Agencia Española de Protección de Datos la que tutela los derechos del ciudadano Mario Costejo frente a la empresa Google, en realidad, el conflicto gravita entre el periódico La Vanguardia y la empresa gestora del «seach engine» o motor de búsqueda de Google. Es decir, quién debe «borrar» los datos para dar satisfacción a la reclamación del particular. La empresa editora de La Vanguardia (bttp://www.lavanguardia.com), además de la edición en papel, ha añadido la edición digital. La publicación digital, además de conferirle mayor visibilidad, resulta una nueva vía para aumentar el negocio (a través de Google News y de Google Search Engine), al incrementar el tráfico y las posibilidades de contratación publicitaria. El periódico no usaba los códigos de exclusión establecidos por la industria (protocolos «robot.txt», «nonindex» o «nonarchive») para impedir la entrada del buscador de Google y evitar la indexación del periódico digital (lo cual no es óbice para que Google cumpla con la Directiva, según el tribunal). Hay que asumir, por tanto, que La Vanguardia aceptaba y «disfrutaba» de las funciones del buscador y localizador de Google. Obviamente, estas cosas no le pasarían al periódico si continuara solo en formato papel, si no fuera digital en Internet y si los motores de búsqueda no existieran. Aunque, por otra parte, el periódico no ha presentado ninguna reclamación o queja al respecto, simplemente contesta ante

19 STJUE de 13 de mayo de 2014, asunto C-131/12, Google Spain, S. L., and Google, Inc., vs. Agencia de Protección de Datos (AEPD) y Mario Costeja González. 
la petición de un ciudadano que pretende la retirada de información en la red. Como bien decía el auto de la Audiencia Nacional: «El buscador solo reproduce los datos que han subido terceros (webs de terceros). Digamos que podría entenderse un "consentimiento tácito o expreso" [...]. Son los editores (webmaster) o el responsable del servidor de alojamiento los que pueden excluir total o parcialmente una determinada información de los índices automáticos de los buscadores (protocolos "robot.txt", "nonindex" o "nonarchive"). Pero, por otro lado, son los buscadores los que localizan y almacenan la información existente en Internet y contribuyen a su difusión facilitando el acceso mediante un índice ordenado». En definitiva, la Audiencia Nacional se pregunta si Google es un responsable directo y/o subsidiario con respecto al titular de la página web o en relación con la autoridad que ordenó la publicación. La otra parte, Google Spain y Google Inc., es la multinacional ya conocida por los anteriores casos, aunque hay que llamar la atención de que en este la reclamación va dirigida a Google como «seach engine» y no a «Google News», aunque, una vez más, se pueda ver, en el fondo de la cuestión, la inevitable conexión.

De las cuestiones planteadas, interesan aquí las que se refieren a la actividad de los buscadores como proveedor de contenidos, en relación con la Directiva 95/46, y las más específicas y concretas, dirigidas a la solución del conflicto. Se admite positivamente que existe «tratamiento de datos» por parte del buscador y que Google Search es «responsable del tratamiento». Importante señalar, al hilo de las anteriores resoluciones, que en esta, y contra la opinión experta del abogado general en la causa, se resuelve atribuyendo «responsabilidad jurídica» a la tecnología, al software y/o a los algoritmos, que son gestionadas por Google ${ }^{20}$. Pero esta no es la posición del tribunal, que entiende que los gestores de los motores de búsqueda son responsables del tratamiento llevado a cabo en sus índices, y su tratamiento se distingue del tratamiento de los editores de periódicos, a los que les asisten otras razones distintas conforme a la Directiva.

Dirimido ese punto, la cuestión principal es a quién tiene que dirigirse el Sr. Costejo, al periódico donde se dio la noticia o a Google, y, si es en este último, por qué habría de borrarse cuando la noticia que se reproduce del origen es veraz, exacta y legal en toda la extensión de la palabra. Por qué en el periódico sigue siendo "legal” y en Google se habría conver-

20 SSTJUE de 23 de marzo de 2010, asuntos C-236/08 y C-238/08, Google France vs. Louis Vuitton, en las que, entre otras sentencias, el Tribunal Europeo determina la responsabilidad de los buscadores de Internet, en tanto en cuanto desempeñen un papel activo que puedan darles conocimiento o control de los datos almacenados. 
tido en ilegal. Cómo ha operado la tecnología para "transformar" lo legal en ilegal, y cómo puede afectar a los modelos de negocio de las noticias. La respuesta final del tribunal es que debe dirigirse al gestor del motor de búsqueda de Google y ejercitar ante el mismo su derecho a la retirada de la información (supresión de los enlaces) que desea que no aparezca (derecho a la privacidad) en los resultados de búsqueda por su nombre, sin necesidad de demostrar perjuicio alguno. El derecho debe ejercerse ante Google, al que no le asisten las mismas excepciones o razones que, conforme a la Directiva, asisten a La Vanguardia en el tratamiento de los datos. El paso del tiempo desde que se produjo el hecho y se publicó la noticia (dieciséis años) hace decaer el posible interés legítimo del tratamiento (el interés general de los usuarios), y los datos resultan no actualizados y excesivos, y deben serlo durante todo el tiempo. Rallo Lombarte se refiere a este paso del tiempo en Internet como la "etenidad de la información", la cual tiene sus efectos, indudablemente, sobre la privacidad ${ }^{21} \mathrm{y}$ en otros derechos fundamentales como el derecho a la información (el interés general decae). Pero habría que reflexionar que el tiempo también se detiene en el papel, pero lo que allí no ocurre y sí en el soporte digital es que esa misma información, que eternamente permanece en la red, se puede "actualizar" cada vez que se produce una búsqueda mediante Google. Esa información "dormida" renace cuando se la presta "atención" de nuevo (la transformación del factor tiempo en Internet). Todo ello con importantes consecuencias jurídicas (por ejemplo, esa información ya no sería pertinente para los procesos democráticos).

Nótese que tanto la defensa de Google como la posición del abogado general sostienen que como la información facilitada por Google proviene de una fuente pública de información (la web del periódico), cuya finalidad del tratamiento de datos vino dada por un «interés informativo» (excepción del art. 9 de la Directiva), y aunque sometidos nuevamente a la Directiva los datos públicos tomados de la web fuente por el buscador, el nuevo tratamiento se vería legitimado en virtud de los arts. 7.f) (interés legítimo), 6.b) y e) (fines históricos, científicos o estadísticos, tanto del tratamiento como su conservación) y el mismo art. 9 (finalidad informativa), entre otros. Es decir, la misma lógica que se ha visto en el caso Satamedia, cuya cesión comercial de los datos y fin lucrativo no ensombrece la finalidad informativa. Sin embargo, aquí, mediante la operación pre-

${ }^{21}$ A. Rallo Lombarte, «El Tribunal de Justicia de la Unión Europea como juez garante de la privacidad en Internet», Teoría y Realidad Constitucional, núm. 39 (2017), p. 603. 
via de determinar «establecimiento» en el Estado miembro y el «recurso a medios», se llega a la conclusión de que los proveedores de servicios comerciales de motor de búsqueda en Internet ofrecen sus servicios de localización de información en el marco de una actividad empresarial que tiene por objeto obtener beneficios de la publicidad a partir de palabras clave. Ello los convierte en empresas, cuya libertad reconoce el art. 16 de la Carta de Derechos Europea con arreglo al Derecho de la Unión Europea y al Derecho nacional. Es decir, la finalidad del motor de búsqueda es principalmente económica. El Tribunal realiza casi un razonamiento circular en los apartados 56 y 57 de la sentencia que podrían criticarse a favor de una conclusión diferente. El estrechamiento en la interpretación, sin embargo, puede justificarse, puesto que la actividad del buscador no es, como se exige en el caso Satamedia, «exclusivamente» periodística o informativa (aunque se puede matizar que todos los medios de comunicación son comerciales, en mayor o menor medida). Además de los intereses de Google y de los anunciantes, el posible interés general del público, que también persigue el motor de búsqueda, queda relegado a los derechos del interesado en este caso. Por tanto, y además, el tratamiento de datos sigue una lógica diferente a la del periódico fuente y no le asisten las mismas razones legítimas para el tratamiento y la permanencia de los datos.

Y es aquí donde la naturaleza de la tecnología (el motor de búsqueda de Google en Internet) muestra aspectos distintivos en los factores tiempo-espacio que cambia lo que es legal en el periódico a ilegal en los resultados de búsqueda:

«(95) En lo que atañe a las solicitudes en el sentido de este art. 12, letra $b$ ), basadas en el supuesto incumplimiento de los requisitos establecidos en el art. 7, letra $f$ ), de la Directiva 95/46 y con arreglo al art. 14, párrafo primero, letra $a$ ), de dicha Directiva, ha de señalarse que cada tratamiento de datos personales debe ser legítimo, en virtud del art. 7, durante todo el periodo en el que se efectúa.

$\mathrm{Si}$, en principio, el tratamiento fue legítimo amparado por los intereses generales del público en la información, este interés y la legitimidad que proporciona para seguir tratando los datos ha decaído. La permanencia en la memoria oculta y en los índices sine die es contraria a la Directiva» ${ }^{22}$.

22 STJUE de 8 de abril de 2014, asuntos C- 293/12 y C-594/12, Digital Rights Ireland y Seitlinger y otros vs. Irish Data Protection Comissioner. Esta sentencia anuló la Directiva 2006/24/CE del Parlamento Europeo y del Consejo, de 15 de marzo de 2006. En la misma se puso de manifiesto los riesgos de conservar los datos y/o información durante largos periodos de tiempo, tales como un estado de vigilancia constante e indiscriminada. 
En definitiva, que los datos deben ser, conforme al art. 6 de la Directiva, exactos, completos, pertinentes, tratados de forma no incompatible con el fin para el que han sido obtenidos, actuales, no excesivos, etc., durante todo el tiempo. Obviamente, después de dieciséis años ya no se pueden considerar actuales, y, por tanto, son excesivos y obsoletos en los resultados que ofrece el motor de búsqueda. Podemos decir que Google los pone de actualidad cada vez que se hace una búsqueda con el nombre del interesado desde cualquier parte del mundo. Pero al cabo del tiempo podríamos decir que ya no se hace por «interés informativo», sino por interés económico del gestor.

Sin embargo, cabe una reflexión: en un principio, cuando Google difundía la información al tiempo o poco después que el mismo periódico, sí mantenía el «interés público general», aunque fuera para la misma actividad publicitaria. Luego parece que no es tanto el carácter mixto comercial/informativo como que sea solo comercial y que cambien los principios y fines que están presentes en las distintas prácticas que propicia Google, que es el buscador de que se trata en este caso. La presencia de la publicidad con su fin comercial no ha sido obstáculo para caracterizar al «periódico convencional en papel» (o cualquier otro medio de comunicación) como medio informativo o medio de comunicación social, cuyo fin es informativo. La necesidad de financiación es necesaria tanto para la prensa digital como para el resto de los actores en Internet. Lo que ocurre aquí es que la nueva tecnología «transforma» la información en «eterna», como dice Rallo Lombarte ${ }^{23}$, y técnicamente la misma práctica se reconvierte en publicitaria y/o comercial. Y el motor de búsqueda puede reactualizar la información «atrayendo la atención» que monetiza publicitariamente.

Tanto en el auto de la Audiencia Nacional como en la conclusiones del abogado general o en la misma sentencia del Tribunal de Luxemburgo, hay razones y razonamientos que, con cierta crítica, podrían sostener que la función principal y necesaria de Google en Internet es organizar y hacer posible el acceso a la información y, por tanto, su misión informativa ineludible siempre, sea en una actividad puramente periodística o comercial. Además, la actividad publicitaria también puede plantearse como ejercicio al derecho a la información y necesaria para sostener el fin último. Quiere decirse con esto que es necesario ahondar más, doctrinalmente, en el necesario equilibrio derecho a la privacidad/derecho a la información referido

${ }^{23}$ A. Rallo Lombarte, «El Tribunal de Justicia de la Unión Europea...», op. cit., p. 603. 
a los buscadores en Internet. El Reglamento de Protección de Datos Personales ${ }^{24}$ ha configurado, finalmente, este derecho al olvido.

Sorrell c. IMS Health Inc. (2011) 25

Este caso del Tribunal Supremo norteamericano, a diferencia de los anteriores, no se produce en el entorno de los medios de comunicación ni resulta manifiestamente del uso de nueva tecnología en la recogida y tratamiento de datos, aunque, obviamente, la inquietud está latente. Sin embargo, se trata de una de las pocas sentencias del Tribunal Supremo americano en materia de datos personales, y su decisión parece altamente interesante tanto desde la perspectiva americana como desde la europea. Efectivamente, llama la atención de todos la calificación de «libertad de expresión e información» la actividad de los demandantes («data miners» y una asociación de empresas farmacéuticas) en la recopilación, tratamiento y cesión de datos de las recetas médicas, sin consentimiento, con un fin de marketing, incluyéndolo dentro del ámbito de protección de la First Amendment. Si bien es cierto que el marco legal de Estados Unidos en la protección de datos (privacy) es diferente al de la Unión Europea, también hay que recordar que justamente es esta una de las áreas, la de sanidad, junto a las de educación y financiera, que en ese país tiene una legislación protectora de datos equiparable a la europea. Por tanto, aunque parezca algo forzado establecer algunas relaciones entre esta sentencia y la anterior (AEPD c. Google) dictada por el Tribunal Europeo, vista en el anterior epígrafe, que dio respuesta a varios casos abiertos con el mismo conflicto en distintos países de la Unión Europea, puede ser útil, al observar los problemas desde diferentes perspectivas para identificar mejor las causas, salvando distancias jurídicas.

Se asume que son dos decisiones de dos altos tribunales radicalmente distintas y de antecedentes jurídicos diametralmente opuestos. Mientras en una, la europea, se refiere a datos públicos, aunque referidos a una persona privada con su nombre, que se tratan y ceden por fuentes públicas con fines publicitarios-informativos; en la otra, la americana, se ceden y tratan datos privados confidenciales, sin consentimiento, referidos a personas identificadas y privadas con un fin de marketing. En el primero, con

${ }^{24}$ Reglamento (UE) núm. 2016/679 del Parlamento Europeo y del Consejo, de 27 de abril de 2016, relativo a la protección de las personas físicas en lo que respecta al tratamiento de datos personales y a la libre circulación de estos datos, y por el que se deroga la Directiva 95/46/CE (reglamento general de protección de datos), art. 17.

25 Sorrell vs. IMS Health Inc. 564 US núm. 10-779 131 S. Ct. 2653 (2011). 
independencia del carácter público de datos y fuentes, se da preferencia al derecho a la privacidad del interesado. Y en el segundo, con independencia del carácter privado (casi íntimo), confidencial, de datos y fuentes, se da preferencia a la libertad de información y expresión comercial. Esta diferencia pone de manifiesto la diferente concepción jurídica en la materia entre Estados Unidos y la Unión Europea.

No se obvia que en Estados Unidos la decisión de la Corte Suprema fue muy criticada por los sectores defensores de la protección de datos o «privacy». Y en Europa, en principio, el uso de datos que revelan la confidencial relación entre paciente-médico es contrario a la Directiva, salvo que tal uso se haga para fines legítimos (investigación, salud...) o, en todo caso, con la despersonalización de los datos. Ahora bien, la sentencia americana lanza una señal de alerta: las leyes o las sentencias que tengan la legítima finalidad de proteger la privacidad o datos personales deben probar rigurosamente los hechos y las razones por las que se restringen estos derechos, y deben soportar un nivel de análisis muy estricto entre finalidad, idoneidad y proporcionalidad de las medidas adoptadas. En otras palabras, deben justificar por qué la misma información dirigida o utilizada por diferentes sujetos, en diferentes ámbitos y con posibles diferentes propósitos puede resultar legal en unos casos y no en otros. En este caso concreto, el Estado de Vermont pretende mediante ley proteger los datos de las recetas médicas; sin embargo, falla en las medidas adoptadas que resultan inconstitucionales por vulnerar la First Amendment, según la decisión de la Corte Suprema. También la sentencia el Tribunal Europeo, en el caso Google, ha provocado muchas incógnitas y algunas críticas respecto a la decisión tomada.

En el litigio del caso Sorrell las partes son, por un lado, el abogado general del Estado de Vermont (que defiende la ley estatal en defensa de la confidencialidad de los datos médicos) y, por otro, una asociación de empresas farmacéuticas y los «data miners» (sujetos dedicados a la minería de datos). Mientras que el primero defiende el derecho a la privacidad de los médicos y sus pacientes frente a la utilización de los datos de las recetas para fines de marketing, los segundos reclaman el uso de esos datos para sus actividades empresariales en el ejercicio de su libertad de expresión e información comercial en el campo de la medicina.

«Vermont contends that its law (1) is necessary to protect medical privacy, including physician confidentiality, avoidance of harassment, and the integrity of the doctor-patient relationship, and (2) is integral to the achievement of the policy objectives of improving public health and reducing healthcare costs». 
Sin embargo, conforme a los demandantes y la propia Corte Suprema, solo se defiende tal privacidad frente a los fabricantes, los «detailers» y los encargados de la «minería de datos», pero no frente a otros a los que los farmacéuticos pueden ceder o vender la misma información. Los «data miners» realizan los informes que describen las conductas médicas basados en los datos de las recetas, que venden a las empresas farmacéuticas fabricantes y que, a su vez, los ceden a los «detailers» para refinar las tácticas de marketing y otras prácticas.

La Corte Suprema afirma que la ley debe someterse a un escrutinio estricto para mostrar su idoneidad en cuanto a sus restricciones y conformidad con la Constitución. Y argumentos tales como: que la información comercial sufre mayores restricciones que la información no comercial; la distinción entre información y expresión, e incluso la equiparación como mercancía de este tipo de información; la privacidad, el acceso a la información estatal que persigue fines de interés general; la injerencia en la decisión libre del médico y que afecta a los pacientes mediante la revelación de las recetas, o argumentos de política sanitaria perseguidos por la ley, son desmontados por el Tribunal Supremo que califica la ley de discriminatoria, favoreciendo un determinado punto de vista. Entiende las actividades de los «detailers» como «libertad de expresión e información comercial» que se impone sobre los intereses de los datos personales (en Estados Unidos no es un derecho fundamental).

El principio de «interés público» se impone en el caso americano, a pesar de la confidencialidad de los datos, pues se prioriza «el mercado de las ideas». En el caso europeo, a pesar de ser datos ya públicos en medios de comunicación, el principio de «interés individual» se impone, pues se prioriza la soberanía de la persona sobre sus datos. Ahora bien, tanto allí como aquí existen excepciones, tales como la utilización para fines de investigación, periodísticos, históricos, de salud, etc. (precisamente las que establece la Vermont's Prescription Confidentiality Law, pero el Tribunal interpreta que discriminan unos en contra de otros).

La cuestión que deviene, por consiguiente, es cómo «defender los datos personales públicos» o información personal pública para proteger la privacidad de la persona, pues con las nuevas tecnologías estos datos «retratan» a su titular en todas las dimensiones. Y sea cual sea el contexto (investigación, fines históricos, periodísticos o comerciales, etc.), y aunque a veces sea «menos fácil», siempre se puede llegar a la identidad y a la privacidad de la persona con los medios electrónicos digitales. 


\section{CONCLUSIONES}

El elemento tecnológico ha transformado los parámetros tiempo-espacio. El analógico era capaz de establecer parámetros de tiempo-espacio definidos que determinaban los mercados, las reglas de la competencia y las modalidades de explotación. En el soporte digital, los parámetros tiempo-espacio se convierten en «viralidad»: el espacio se manifiesta en distintos «contextos» y el tiempo en «atención». Atención que, o bien se produce instantáneamente por el click en la información que capta la atención, o bien por la «visibilidad» que se adquiere al difundirse en muchos espacios, o bien, después de que la información se ha difundido de un sitio a otro y permanece en diferentes webs técnicamente accesible «casi eternamente», porque se pueda «reactualizar», reutilizar y explotar de diferentes formas y con distintos fines.

El proceso manual/proceso automático que se sustancia en uno u otro (papel o digital) es relevante a efectos no solo de identificar derechos y su ejercicio, sino también de determinar la responsabilidad jurídica de los actos y procesos llevados a cabo con la información y/o los datos. Lo que, en definitiva, se ha visto es que la nueva tecnología transforma, a veces, en ilegal lo que es legal en papel (y al revés) y hace surgir derechos. Se va visto cómo el elemento tecnológico, por sus características y funcionamiento, hace «acallar» algunos derechos, pero también activa o genera otros (que no eran posibles en papel) y que solo son posibles en la naturaleza y dinámica digital en la red.

En el digital, la tecnología reduce, en principio, a un instante el tiempo de explotación de la noticia (en tanto que nueva), lo que sofoca las posibilidades de recobrar la inversión realizada por el productor en lo que se refiere al «interés de la vigencia de la noticia». El valor de explotación de la noticia en papel es la actualidad, la exclusiva periodística, el rigor y fiabilidad unido a ello. Sin embargo, en el periodismo en la web este valor se traduce en instantaneidad, incluso en el «en vivo y en directo». Y su valor como «noticia» para el productor se reduce a ese instante, debido a la actividad inmediata de los agregadores (sean parásitos o transformadores). Después, la tecnología permite otras formas de explotación por la «reutilización de las informaciones» y la explotación de los datos con muy distintos fines y utilidades, entre ellas el «big data analitics».Obviamente, todo esto no es inocuo para los derechos fundamentales, cuyo contenido se desdibuja y la relación con otros derechos se vuelve conflictiva en algunos contextos. 
El impacto que el derecho a la información recibe debido a la tecnología digital, se manifiesta en el impacto de este derecho sobre el resto de los derechos fundamentales. Y, debido al efecto irradiante de estos, también se hace notar en todas las instituciones democráticas. Asimismo, impacta en la sistematicidad propia del ordenamiento jurídico y en la propia unidad del sistema de derechos y libertades constitucionales. 